\title{
The Changes of Carbon Emission in China's Industrial Sectors from 2002 to 2010: A Structural Decomposition Analysis and Input-Output Subsystem
}

\author{
Guoxing Zhang ${ }^{1,2}$ and Mingxing Liu ${ }^{1}$ \\ ${ }^{1}$ School of Management, Lanzhou University, Lanzhou 730000, China \\ ${ }^{2}$ School of Management, Xi'an Jiaotong University, Xian 710049, China \\ Correspondence should be addressed to Guoxing Zhang; guoxingzh@lzu.edu.cn
}

Received 1 March 2014; Accepted 30 April 2014; Published 13 May 2014

Academic Editor: Chuangxia Huang

Copyright ( $\odot 2014$ G. Zhang and M. Liu. This is an open access article distributed under the Creative Commons Attribution License, which permits unrestricted use, distribution, and reproduction in any medium, provided the original work is properly cited.

Based on 2002-2010 comparable price input-output tables, this paper first calculates the carbon emissions of China's industrial sectors with three components by input-output subsystems; next, we decompose the three components into effect of carbon emission intensity, effect of social technology, and effect of final demand separately by structure decomposition analysis; at last, we analyze the contribution of every effect to the total emissions by sectors, thus finding the key sectors and key factors which induce the changes of carbon emissions in China's industrial sectors. Our results show that in the latest 8 years five departments have gotten the greatest increase in the changes of carbon emissions compare with other departments and the effect of final demand is the key factor leading to the increase of industrial total carbon emissions. The decomposed effects show a decrease in carbon emission due to the changes of carbon emission intensity between 2002 and 2010 compensated by an increase in carbon emissions caused by the rise in final demand of industrial sectors. And social technological changes on the reduction of carbon emissions did not play a very good effect and need further improvement.

\section{Introduction}

Since China is the largest $\mathrm{CO}_{2}$ emitter in the word, there is a huge pressure when facing the problems of global warming. In the year of 2009 the Chinese government promised to reduce carbon dioxide emissions per unit of GDP by $40-45 \%$ in 2020 to be less than 2005 levels. In addition, China has set a target of reducing $\mathrm{CO}_{2}$ intensity per unit GDP by $17 \%$ in 2015 to be less than 2010 levels in the twelfth five-year plan [1]. Since reform and opening, China's industry become the main sector of carbon emissions, it's production accounting GDP $40.1 \%$ but it consumed $67.9 \%$ of the country's energy and released $83.1 \%$ of the country's carbon dioxide [2]. Moreover, the data of Chinese Energy Statistical Yearbook (2012) shows that China's total carbon emissions in the industrial sectors indicated a continuous upward trend [3]. Obviously, investigating the underlying reasons of the carbon emission changes in China's industrial sectors and studying different factors contributed to the total carbon emissions are essential for developing rational reduction policies and achieving emission reduction targets.

Much of the existing literature focuses on analyzing the influence factors leading to the changes of carbon emissions in the industrial sectors by different methods. For example, Ren et al. [4] and Lin and Moubarak [5] adopt the Log Mean Divisia Index method to explore the impact factors of the total carbon emissions in China's manufacturing industry and textile industry, respectively, during different years. The same method is used by Zhao et al. [6] and Shao et al. [7] to analyze the main factors responsible for the industrial carbon emissions in Shanghai and Tianjin, respectively. A decomposition analysis based on an additive Log Mean Divisia Index is developed by Sheinbaum-Pardo et al. [8] to explain the changes in $\mathrm{CO}_{2}$ emissions related to energy consumption of the manufacturing industries in Mexico. Akbostanci et al. [9] use the same method to decompose the changes in the $\mathrm{CO}_{2}$ emissions of manufacturing industry in Turkey. Hammond and Norman [10] use decomposition analysis to separate 
the contributions of changes in output, industrial structure, energy intensity, fuel mix, and electricity emission factor to the reduction in carbon emissions in UK's manufacturing. Priambodo and Kumar [11] use the energy use survey and detailed energy audits in Indonesia's industries to analyze the reasons leading to the increase of carbon emission. Huang and $\mathrm{Wu}$ [12] use two-tier KLEM input-output structural decomposition analysis to analyze the factors that lead to changes in $\mathrm{CO}_{2}$ emissions in Taiwan's industrial sectors between 1996 and 2006. González and Martínez [13] identify the factors that have influenced the changes in the carbon dioxide emissions in the Mexican industrial sectors by the use of the Refined Laspeyres Index method. Caiman and Brian [14] combine physical and economic output data to analyze energy and $\mathrm{CO}_{2}$ emissions trend in the Ireland industry.

Structure decomposition techniques have been applied to numerous economic and environmental subjects and often used to analyze energy intensities and emission coefficients. For example, Yuan and Cheng [15] use structural decomposition method to analyze the growth reasons of carbon emissions in China during 1992-2005. Zhao et al. [16] apply the structure decomposition techniques to study the energy consumption of urban residents in China during 1998 to 2007. Liang and Zhang [1] and Tian et al. [17], based on environment input-output structure decomposition techniques, analyze the driving force of carbon emissions in China's Jiangsu province and Beijing municipality, respectively. By combining structural decomposition and inputoutput analysis Guan et al. [18] assess the driving forces of China's $\mathrm{CO}_{2}$ emissions from 1980 to 2030. Brizga et al. [19] use structural decomposition analysis to identify the drivers of change for $\mathrm{CO}_{2}$ emissions in the Baltic states between 1995 and 2009. Cellura et al. [20] apply an energy and environmental extended input-output model, combined with SDA, to assess the indirect energy consumption and air emission changes related to Italian households' consumption. Wood [21] studies the factors of greenhouse gas emissions in Australia by applying a structure decomposition technique method. The scholars above mainly use the input-output structural decomposition method to analyze the whole economy's carbon emissions or energy consumption of some place. When a particular industry or particular sectors need to be researched, we can apply the input-output subsystems. Alcántara and Padilla [22] use a subsystem model to study the $\mathrm{CO}_{2}$ emissions of the Spanish service sector. Cardenete and Fuentes [23] analyze the $\mathrm{CO}_{2}$ emissions of Spanish energy activities using a subsystem representation within a social accounting matrix model. Butnar and Liop [24] study the influence factors of carbon emissions in Spain during 2000 to 2005 by applying input-output subsystem and structure decomposition analysis.

In summary, all these contributions above focus on explaining the changes in total emissions of the economy. It would be interesting, however, to analyze the changes in those emissions caused by a specific sector. And, as far as I know, no contributions in the literature have studied the changes in industrial sectors by applying structural decomposition within a subsystem approach in China. And there are a sum of literature studied the changes of carbon emissions in
China's industrial sectors by applying Index method, while this approach has a disadvantage in analyzing the indirect carbon emissions caused by the industrial sectors. In this paper, we analyze the influence factors behind the changes of carbon emission in China's industry sectors during 2002 to 2010 by applying structural decomposition analysis and input-output subsystems. Because this method can comprehensively analyze various direct and indirect influential factors relied on input-output model.

\section{Method and Data}

2.1. Construction of Industrial Input-Output Subsystem Model. First, we decompose the $N$ accounts of an input-output system into $I$ sectors belonging to the industrial subsystem and $S$ sectors not belonging to the industrial subsystem.

$A=\left(\begin{array}{ll}A_{i i} & A_{i s} \\ A_{s i} & A_{s s}\end{array}\right)$ is the matrix of direct consumption coefficient of input-output tables, in which, $A_{i i}$ is the matrix of direct consumption coefficient of industrial sectors, $A_{s s}$ is the matrix of direct consumption coefficient of nonindustrial sectors, $A_{i s}$ is the matrix of direct consumption coefficient of nonindustrial sectors to the industrial sectors, and $A_{s i}$ is the matrix of direct consumption coefficient of industrial sectors to the nonindustrial sectors.

$B=(I-A)^{-1}=\left(\begin{array}{cc}B_{i i} & B_{i s} \\ B_{s i} & B_{s s}\end{array}\right)$ is Leontief inverse matrix; the definition of $B_{i i}, B_{i s}, B_{s i}$, and $B_{s s}$ is the same as direct consumption coefficient.

$X=\left(\begin{array}{l}X^{i} \\ X^{S}\end{array}\right)$ denotes the vector of total output, in which $X^{i}$ is the total output of industrial sectors; $X^{S}$ is the total output of nonindustrial sectors.

$Y=\left(\begin{array}{c}Y^{i} \\ Y^{S}\end{array}\right)$ denotes the vector of final demand, $Y^{i}$ is the final demand of industrial sectors and $Y^{S}$ is the final demand of nonindustrial sectors.

$C^{i}$ is the column vector of carbon emissions per unit of production in the industrial sectors.

$C^{s}$ is the column vector of carbon emissions per unit of production in the nonindustrial sectors.

$\Lambda$ denotes diagonalization of the corresponding vector.

' denotes transposition of the corresponding matrix or vector.

The input-output representation can be written as follows:

$$
\left(\begin{array}{ll}
A_{i i} & A_{i s} \\
A_{s i} & A_{s s}
\end{array}\right)\left(\begin{array}{l}
X^{i} \\
X^{S}
\end{array}\right)+\left(\begin{array}{c}
Y^{i} \\
Y^{S}
\end{array}\right)=\left(\begin{array}{c}
X^{i} \\
X^{S}
\end{array}\right) .
$$

And the solution of total output is

$$
\begin{aligned}
\left(\begin{array}{l}
X^{i} \\
X^{S}
\end{array}\right) & =\left[\left(\begin{array}{ll}
I & 0 \\
0 & I
\end{array}\right)-\left(\begin{array}{ll}
A_{i i} & A_{i s} \\
A_{s i} & A_{s s}
\end{array}\right)\right]^{-1}\left(\begin{array}{c}
Y^{i} \\
Y^{S}
\end{array}\right) \\
& =\left(\begin{array}{ll}
B_{i i} & B_{i s} \\
B_{s i} & B_{s S}
\end{array}\right)\left(\begin{array}{c}
Y^{i} \\
Y^{S}
\end{array}\right) .
\end{aligned}
$$


By taking this solution into the left of (1) and assuming that the nonindustrial sectors only produce for the intermediate demand (i.e., $Y^{s}=0$ ), then

$$
\left(\begin{array}{ll}
A_{i i} & A_{i s} \\
A_{s i} & A_{s s}
\end{array}\right)\left(\begin{array}{ll}
B_{i i} & B_{i s} \\
B_{s i} & B_{s s}
\end{array}\right)\left(\begin{array}{c}
Y^{i} \\
0
\end{array}\right)+\left(\begin{array}{c}
Y^{i} \\
0
\end{array}\right)=\left(\begin{array}{c}
X_{i}^{i} \\
X_{i}^{s}
\end{array}\right) .
$$

Let $X_{i}^{i}$ be the production of industrial sectors needed to cover the final demand of themselves, and let $X_{i}^{s}$ be the production of nonindustrial sectors needed to cover the final demand of industrial sectors. Equation (3) can be written as

$$
\begin{gathered}
A_{i i} B_{i i} Y^{i}+A_{i s} B_{s i} Y^{i}+Y^{i}=X_{i}^{i}, \\
A_{s i} B_{i i} Y^{i}+A_{s s} B_{s i} Y^{i}=X_{i}^{s} .
\end{gathered}
$$

Equation (4) denotes the production of industrial sectors needed to cover the final demand of themselves. On the left hand side, $A_{i i} B_{i i} Y^{i}$ contains the production needed by the industrial sectors from the other industrial sectors or themselves to obtain the own production. $A_{i s} B_{s i} Y^{i}$ shows the inputs of the industrial sectors subsystem required by the nonindustrial sectors to obtain the production that industrial sectors demand to them. These two components together show the internal components that affect the production of industrial sectors. $Y^{i}$ is the final demand for the industrial sectors subsystem which can be considered as a demand level component. Equation (5) shows the production of the nonindustrial sectors needed to cover the final demand of the industrial sectors; therefore, we can consider it as an external component.

According to (4) and (5), first we calculate the total production of industrial sectors with three components, then multiply the carbon emissions per unit of production in the industrial sectors and nonindustrial sectors, and, finally, diagonalize $Y^{i}$, thus obtaining the carbon emissions of every industrial sector composed of three parts, calculated as follows:

$$
\begin{gathered}
\text { DLC }=C^{i^{\prime}} Y^{i}, \\
\mathrm{IC}=C^{i^{\prime}}\left(A_{i i} B_{i i}+A_{i s} B_{s i}\right) Y^{i}, \\
\mathrm{EC}=C^{s^{\prime}}\left(A_{s i} B_{i i}+A_{s s} B_{s i}\right) Y^{i} .
\end{gathered}
$$

The above three equations denote the demand level component, internal component, and external component that contribute to the total carbon emissions of industrial sectors, respectively. So the total carbon emissions can be written as

$$
\begin{aligned}
E= & \mathrm{DLC}+\mathrm{IC}+\mathrm{EC} \\
= & C^{i^{\prime}} \stackrel{\Lambda}{Y^{i}}+C^{i^{\prime}}\left(A_{i i} B_{i i}+A_{i s} B_{s i}\right) Y^{i} \\
& +C^{s^{\prime}}\left(A_{s i} B_{i i}+A_{s s} B_{s i}\right) Y^{i} .
\end{aligned}
$$

2.2. Structural Decomposition of the Input-Output Subsystem Model. Input-output structural decomposition analysis technique is a method of analyzing the reasons of economic changes through the comparative static analysis of key parameters. There are many decomposition forms, but the polar decomposition method is used in this paper. From a mathematical point of view, such method looks not only good but also comparable between the weights of different factors, furthermore, there are no interaction terms difficult to explain, so the method get widely recognized by the international academic community [25].

Some matrix and symbols will be illustrated as follows:

$$
\begin{aligned}
& \bar{A}=A_{i i} B_{i i}+A_{i s} B_{s i}, \\
& \bar{B}=A_{s i} B_{i i}+A_{s s} B_{s i} .
\end{aligned}
$$

The symbol $\Delta$ denotes the changes of two different periods, that is, final value minus initial value. Subscripts 0,1 denote initial value and final value of the corresponding matrix or vector, respectively. In order to calculate the changes of carbon emissions in two different periods,

$$
\Delta E=\Delta \mathrm{DLC}+\Delta \mathrm{IC}+\Delta \mathrm{EC} .
$$

The first term in expression (11) can be decomposed as follows:

$$
\begin{aligned}
\Delta \mathrm{DLC} & =C_{1}^{i^{\prime}} Y_{1}^{\Lambda}-C_{0}^{i^{\prime}} Y_{0}^{Y^{i}} \\
& =\frac{1}{2}\left(\Delta C^{i^{\prime}}\right)\left(\begin{array}{cc}
\Lambda & \Lambda \\
Y_{0}^{i} & +Y_{1}^{i}
\end{array}\right)+\frac{1}{2}\left(C_{0}^{i^{\prime}}+C_{1}^{i^{\prime}}\right) \Delta Y^{i} .
\end{aligned}
$$

The first element in expression (12), $\Delta \mathrm{CEE}_{\mathrm{DLC}}=(1 / 2)$ $\left(\Delta C^{i^{\prime}}\right)\left(Y_{0}^{i}+Y_{1}^{i}\right)$, denotes carbon emission intensity effect and shows the contribution of changes in the carbon emission intensities of the industrial sectors to the changes in the demand level component. $\Delta \mathrm{DE}_{\mathrm{DLC}}=(1 / 2)\left(C_{0}^{i^{\prime}}+C_{1}^{i^{\prime}}\right) \Delta Y^{i}$ denotes demand effect and shows how the changes in the demand for industrial sectors contribute to the changes in the demand level component.

The second component in expression (11) can be decomposed as

$$
\begin{aligned}
\Delta \mathrm{IC}= & C_{1}^{i^{\prime}} \bar{A}_{1} Y_{1}^{i}-C_{0}^{i^{\prime}} \bar{A}_{0} Y_{0}^{i} \\
= & \frac{1}{2} \Delta C^{i^{\prime}}\left(\bar{A}_{0} Y_{0}^{i}+\bar{A}_{1} Y_{1}^{i}\right) \\
& +\frac{1}{2}\left[C_{0}^{i^{\prime}}(\Delta \bar{A}) Y_{1}^{i}+C_{1}^{i^{\prime}}(\Delta \bar{A}) Y_{0}^{i}\right] \\
& +\frac{1}{2}\left(C_{0}^{i^{\prime}} \bar{A}_{0}+C_{1}^{i^{\prime}} \bar{A}_{1}\right) \Delta Y^{i} .
\end{aligned}
$$

In which, $\Delta \mathrm{CEE}_{\mathrm{IC}}=(1 / 2) \Delta C^{i^{\prime}}\left(\bar{A}_{0} Y_{0}^{i}+\bar{A}_{1} Y_{1}^{i}\right)$ represents carbon emission intensity effect and shows the contribution 
of changes in the carbon emission intensities of the industrial sectors to the changes in the internal component. $\Delta \mathrm{TE}_{\mathrm{IC}}=$ $(1 / 2)\left[C_{0}^{i^{\prime}}(\Delta \bar{A}) Y_{1}^{i}+C_{1}^{i^{\prime}}(\Delta \bar{A}) Y_{0}^{i}\right]$ denotes effect of economic and technological changes and shows how the changes in the economy and technology contribute to the changes in the internal component. $\Delta \mathrm{DE}_{\mathrm{IC}}=(1 / 2)\left(C_{0}^{i^{\prime}} \bar{A}_{0}+C_{1}^{i^{\prime}} \bar{A}_{1}\right) \Delta Y^{i}$ represents demand effect and shows how the changes in the demand for industrial sectors contribute to the changes in the internal component.

The third component in expression (11) can be decomposed as

$$
\begin{aligned}
\Delta \mathrm{EC}= & C_{1}^{S^{\prime}} \bar{B}_{1} Y_{1}^{i}-C_{0}^{S^{\prime}} \bar{B}_{0} Y_{0}^{i} \\
= & \frac{1}{2} \Delta C^{S^{\prime}}\left(\bar{B}_{0} Y_{0}^{i}+\bar{B}_{1} Y_{1}^{i}\right) \\
& +\frac{1}{2}\left[C_{0}^{S^{\prime}}(\Delta \bar{B}) Y_{1}^{\Lambda}+C_{1}^{S^{\prime}}(\Delta \bar{B}) Y_{0}^{i}\right] \\
& +\frac{1}{2}\left(C_{0}^{S^{\prime}} \bar{B}_{0}+C_{1}^{S^{\prime}} \bar{B}_{1}\right) \Delta Y^{i} .
\end{aligned}
$$

The first element in expression (14), $\Delta \mathrm{CEE}_{\mathrm{EC}}=(1 / 2) \Delta C^{S^{\prime}}$ $\left(\bar{B}_{0} \stackrel{\Lambda}{i}_{0}^{i}+\bar{B}_{1}{ }_{Y_{1}^{i}}\right)$, represents carbon emission intensity effect and shows the contribution of changes in the carbon emission intensities of the nonindustrial sectors to the changes in the external component. $\Delta \mathrm{TE}_{\mathrm{EC}}=(1 / 2)\left[C_{0}^{S^{\prime}}(\Delta \bar{B}) Y_{1}^{i}+C_{1}^{S^{\prime}}(\Delta \bar{B}) Y_{0}^{i}\right]$ denotes effects of economic and technological change and shows the contribution of changes in the economy and technology of the nonindustrial sectors to the changes in the external component. $\Delta \mathrm{DE}_{\mathrm{EC}}=(1 / 2)\left(C_{0}^{S^{\prime}} \bar{B}_{0}+C_{1}^{S^{\prime}} \bar{B}_{1}\right) \Delta Y^{i}$ represents demand effect and shows how the changes in the demand for industrial sectors contribute to the changes in the external component.

According to the above analysis, the changes of total carbon emissions also can be written as follows:

$$
\begin{aligned}
\Delta E= & \Delta \mathrm{CEE}+\Delta \mathrm{TE}+\Delta \mathrm{DE} \\
= & \Delta \mathrm{CEE}_{\mathrm{DLC}}+\Delta \mathrm{CEE}_{\mathrm{IC}}+\Delta \mathrm{CEE}_{\mathrm{EC}}+\Delta \mathrm{TE}_{\mathrm{IC}} \\
& +\Delta \mathrm{TE}_{\mathrm{EC}}+\Delta \mathrm{DE}_{\mathrm{DLC}}+\Delta \mathrm{DE}_{\mathrm{IC}}+\Delta \mathrm{DE}_{\mathrm{EC}} .
\end{aligned}
$$

In which, $\triangle \mathrm{CEE}$ represents the contribution of total carbon emission intensity effect to the changes of total carbon emissions. $\triangle \mathrm{TE}$ denotes the changes of economy and technology contribute to the changes of total carbon emissions. $\triangle \mathrm{DE}$ shows the changes of final demand in the industrial sectors that contribute to the changes of total carbon emissions.

2.3. Date Preparation. Since Chinese input-output tables are compiled every five years, at the year with the last number being 2 or 7 , and the extended input-output tables are compiled at the year with the last number being 0 or 5 , the annual data used in this paper are those of the years 2002, 2007, and 2010 and data derived from the National Bureau of Statistics website [26]. According to National Industry Classification in China and taking the existing input-output tables sector classification into account, we set up 33 sectors (Table 1), including 24 industrial sectors and 9 nonindustrial sectors, according to need we unified the sectors in the inputoutput table and adjusted the positions of them (industrial sectors from 1 to 24). Since current price input-output table cannot reflect the real economic change after deducting price factors, the current price input-output tables need to be converted into comparable price input-output table. In this paper, we transferred the 2007 and 2010 current price input-output tables into 2002 comparable price input-output tables with index reduction method. The specific compilation method refers to "China 1992-2005 comparable price inputoutput series tables and analysis" edited by Liu and Peng [27]. In the process of compiling the comparable price inputoutput tables, the price indexes we needed come from China Statistical Yearbook.

Though there are no direct statistical data of carbon emissions of various industries in China, there are statistical data of energy consumption by sectors and carbon emissions are mainly derived from the consumption of a variety of energy. So, this paper calculated the direct carbon emissions of various industries according to the annual data of energy consumption by sectors and the carbon emission factors of different energy sources. And the carbon emission factors are announced by the Intergovernmental Panel on Climate, the annual data of energy consumption by sectors derived from China Energy Statistical Yearbook, the sectors also consolidated according to our need. Considering the energy statistics caliber of China Energy Statistical Yearbook and the availability of energy carbon emission factors, we selected coal, crude oil, gasoline, kerosene, diesel oil, fuel oil, and natural gas; these seven kinds of energy are calculated as follows:

$$
c_{i}=\sum^{j} c_{i j}=\sum^{j} m_{i j} \times k_{j},
$$

where $c_{i}$ represents the direct total carbon emissions of sector I, $c_{i j}$ shows the carbon emissions of sector I consuming the $j$ th kind of fuel, $m_{i j}$ represents the consumption of sector I to the $j$ th kind of fuel, and $k_{j}$ shows the carbon emission factors of the $j$ th kind fuel. After getting the carbon emissions by sectors, we divided them by the total output of the corresponding sectors, so we got the carbon emissions per unit of output by sectors.

\section{Result and Discussion}

3.1. Analyzing the Contribution of DLC, IC, and EC to the Changes of Total Carbon Emissions. Table 2 shows the changes of total carbon emissions mainly consisting of three components, namely, the demand level component, the internal component, and the external component. In the past eight years, the total carbon emissions of Chinese industrial 
TABLE 1: Sectoral classification of the input-output tables.

\begin{tabular}{|c|c|}
\hline 1 & Mining and washing of coal \\
\hline 2 & Extraction of petroleum and natural gas \\
\hline 3 & Mining and processing of metal ores \\
\hline 4 & Mining and processing of nonmetal ores \\
\hline 5 & Manufacture of foods and tobacco \\
\hline 6 & Manufacture of textile \\
\hline 7 & $\begin{array}{l}\text { Manufacture of wearing apparel, leather, feather, and related } \\
\text { products }\end{array}$ \\
\hline 8 & Processing of timber, manufacture of furniture \\
\hline 9 & $\begin{array}{l}\text { Printing and manufacture of articles for culture and } \\
\text { education }\end{array}$ \\
\hline 10 & $\begin{array}{l}\text { Processing of petroleum, coking, and processing of nuclear } \\
\text { fuel }\end{array}$ \\
\hline 11 & Manufacture of chemical products \\
\hline 12 & Manufacture of nonmetallic mineral products \\
\hline 13 & Smelting and pressing of metals \\
\hline 14 & Manufacture of metal products \\
\hline 15 & Manufacture of general and special purpose machinery \\
\hline 16 & Manufacture of transport equipment \\
\hline 17 & Manufacture of electrical machinery and equipment \\
\hline 18 & $\begin{array}{l}\text { Communication equipment, computers, and other electronic } \\
\text { equipment }\end{array}$ \\
\hline 19 & $\begin{array}{l}\text { Manufacture of measuring instruments and machinery for } \\
\text { cultural activity and office work }\end{array}$ \\
\hline 20 & Other manufacturing \\
\hline 21 & Recycling and disposal of waste \\
\hline 22 & Production and distribution of electric power and heat power \\
\hline 23 & Production and distribution of gas \\
\hline 24 & Production and distribution of water \\
\hline 25 & Construction \\
\hline 26 & Transport and storage \\
\hline 27 & Post \\
\hline 28 & Wholesale and retail trade \\
\hline 29 & Hotel and restaurants \\
\hline 30 & Finance and insurance \\
\hline 31 & Real estate \\
\hline 32 & Other services \\
\hline 33 & $\begin{array}{l}\text { Farming, forestry, animal husbandry, fishery, and water } \\
\text { conservancy }\end{array}$ \\
\hline
\end{tabular}

sectors increased to $5.34 \times 10^{8}$ tons. Viewing from these three different components (DLC, IC and EC), though the changes of industrial demand level decreased the total carbon emissions $1.00 \times 10^{7}$ tons, it is far less than the increase in total carbon emissions caused by the changes of industrial internal component and external component; they are 4.55 $\times 10^{8}$ tons and $8.83 \times 10^{7}$ tons, respectively. So we can know that industrial internal component and external component are the main reasons leading to an overall increase in total carbon emissions. From Table 2 we also can learn that in the latest 8 years the following five departments increased the most in the changes of carbon emissions: transportation equipment, manufacture of general and special purpose machinery, manufacture of electrical machinery and equipment, manufacture of communication equipment computers and other electronic equipment, and manufacture of foods and tobacco; their total carbon emissions increased to $1.47 \times$ $10^{8}$ tons, $1.31 \times 10^{8}$ tons, $1.28 \times 10^{8}$ tons, $7.51 \times 10^{7}$ tons, and $5.97 \times 10^{7}$ tons.

When divided 2002-2010 into two periods; Table 2 shows that the first five years due to the changes of demand level in industrial sectors make the total carbon emissions increase to $5.38 \times 10^{6}$ tons, while the next three years make the carbon emissions decreased to $1.54 \times 10^{7}$ tons. During 20022007, the total carbon emissions increased to $1.24 \times 10^{8}$ tons caused by the changes of internal component of industrial sectors, and during 2007-2010, due to the changes of internal component of industrial sectors, it makes the total carbon emissions increase to $1.24 \times 10^{8}$ tons. During 2002-2007, the total carbon emissions increased to $5.77 \times 10^{7}$ tons caused by the changes of external component of industrial sectors, and during 2007-2010, due to the changes of external component of industrial sectors, the total carbon emissions increased to $3.06 \times 10^{7}$ tons. Though the two periods are asymmetric, the above data also can illustrate the level of demand structure of the industrial sectors gradually improved; it is conducive to the reduction of the total carbon emissions. And the changes of internal and external components slowing the increase of total carbon emissions also indicate the internal and external components of the industrial sectors conducive to the reduction of the total carbon emissions. It can be seen that some good results have been achieved due to the carbon reduction policy implemented by the government in recent years. However, in order to achieve a further improvement in carbon emissions, some appropriate management policies and measures should be implemented regarding the carbonintensive enterprises. In the following we will analyze the two main components (IC and EC) of the five industrial sectors whose carbon emissions increased the most, so as to understand the underlying factors leading to the increase of carbon emissions in these sectors.

3.2. Structure Decomposition Analysis of the Main Components of the Carbon Emissions in the Key Sectors. From Table 2 we already know the five sectors whose carbon emissions increased the most, following structure decomposition analysis of the main component of the carbon emissions in the five sectors. The results are shown in Table 3; we first decompose the internal and external component of the industrial sectors into carbon emission intensity effect, effect of social technology, and effect of final demand. During 2002-2007, the first quadrant of Table 3 shows the five industrial sectors because the internal component leading to the increase of total carbon emissions is mainly caused by the effects of social technology and effect of final demand, while carbon emission intensity effect promoted the reduction of carbon emissions. The third quadrant of Table 3 shows the five industrial sectors due to the external component leading to the increase of total carbon emissions mainly caused by the effect of final 
TABLE 2: The changes of carbon emissions in the three components in different periods.

\begin{tabular}{|c|c|c|c|c|c|c|c|}
\hline \multirow{2}{*}{ Sectors } & \multicolumn{2}{|c|}{$\Delta \mathrm{DLC}$} & \multicolumn{2}{|c|}{$\Delta \mathrm{IC}$} & \multicolumn{2}{|c|}{$\Delta \mathrm{EC}$} & \multirow{2}{*}{$\begin{array}{c}\text { Total } \\
2002-2010\end{array}$} \\
\hline & 2002-2007 & 2007-2010 & 2002-2007 & 2007-2010 & $2002-2007$ & 2007-2010 & \\
\hline 1 & -53.74 & -61.1 & -34.13 & -59.67 & -7.62 & -11.77 & -228.04 \\
\hline 2 & -72.96 & -61.15 & -172.18 & -55.97 & -26.12 & -6.92 & -395.31 \\
\hline 3 & -77.17 & -12.58 & -178.95 & -93.69 & -31.27 & -15.86 & -409.52 \\
\hline 4 & -5.01 & -1.59 & -10.44 & -5.77 & -2.27 & -1.05 & -26.14 \\
\hline 5 & 33.64 & 3.1 & 238.89 & 130.34 & 117.22 & 73.96 & 597.15 \\
\hline 6 & 68.69 & -17.57 & 220.98 & -59.97 & 43.35 & -5.56 & 249.93 \\
\hline 7 & 19.18 & -1.02 & 275.42 & -7.17 & 60.11 & 9.4 & 355.92 \\
\hline 8 & 16.58 & 0.94 & 115.13 & 5.92 & 26.25 & 1.53 & 166.35 \\
\hline 9 & 4.35 & -3.35 & 27.08 & -7.11 & 3.55 & 0.11 & 24.64 \\
\hline 10 & -30.18 & -12.78 & -39.18 & -14.82 & -5.27 & -1.06 & -103.29 \\
\hline 11 & -15.14 & 4.34 & -15.44 & 10.35 & -2.45 & 2.07 & -16.27 \\
\hline 12 & -8.96 & -26.47 & 16.37 & -17.27 & 1.02 & -2.37 & -37.67 \\
\hline 13 & 44.67 & -101.66 & 39.07 & -113.45 & 4.77 & -12.7 & -139.3 \\
\hline 14 & 24.96 & -8.88 & 227.13 & -101.32 & 21.45 & -9.21 & 154.13 \\
\hline 15 & 54.57 & 23.28 & 664.81 & 419.01 & 81.33 & 65.25 & 1308.26 \\
\hline 16 & 34.25 & 47.93 & 680.44 & 517.39 & 100.93 & 90.94 & 1471.88 \\
\hline 17 & 24.54 & 21.74 & 652.46 & 441.18 & 76.14 & 66.58 & 1282.64 \\
\hline 18 & 23.55 & 17.07 & 420.87 & 158.12 & 88.17 & 43.3 & 751.08 \\
\hline 19 & 0.55 & -0.82 & 17.63 & -16.4 & 3.2 & -2.48 & 1.68 \\
\hline 20 & 7.49 & 17.14 & 139.67 & 80.74 & 23.25 & 17.72 & 286.02 \\
\hline 21 & -0.94 & -1.82 & -8.16 & -5.85 & -1.52 & -1.44 & -19.72 \\
\hline 22 & -42.79 & -4.47 & 28 & -9.54 & 1.23 & -1.31 & -28.88 \\
\hline 23 & -3.24 & 4.53 & 4.19 & 21.2 & 0.35 & 3.37 & 30.4 \\
\hline 24 & 6.86 & 20.99 & 6.2 & 20.29 & 1.31 & 3.87 & 59.52 \\
\hline Total & 53.76 & -154.19 & 3315.86 & 1236.55 & 577.11 & 306.36 & 5335.45 \\
\hline
\end{tabular}

Note: unit is $10^{5}$ tons.

demand. However, during 2007-2010, the second quadrant of Table 3 shows the internal component of the five industrial sectors leading to the increase of total carbon emissions mainly caused by the effect of final demand. From the four quadrants we can know that the external component of the five industrial sectors leading to the increase of total carbon emissions is mainly caused by the effect of social technology and effect of final demand.

From the above analysis of the five key sectors we can learn that the social economic technologies of industrial sectors are improving, conducive to the reduction of total carbon emissions, while the social economic technologies of nonindustrial sectors are cutting down, leading to the increase of total carbon emissions. Carbon emission intensity effect is not only conducive to the reduction of carbon emissions caused by internal component but also conducive to the carbon emissions reduction caused by external component in this five sectors. However, the effect of final demand just played a opposite role, it contributed to the increase of carbon emissions both in the internal component and external component. Analyzing from the whole time 20022010, the contribution of carbon emission intensity effect on the reduction of carbon emissions is improving, while the increase in carbon emissions caused by the effect of final demand is also serious. Therefore, in order to control the increase of total carbon emissions in China's industrial sectors, we should pay more attention to the final demand. And at the same time we should also pay attention to the improvement of social and economical technology, because they still have much room for improvement.

3.3. Analyzing the Contribution of CEE, TE, and DE to the Changes of Total Carbon Emissions. Table 4 shows the carbon emission intensity effect, the effect of social technology, and the effect of final demand contributing to the total carbon emissions. We also can know that the total carbon emissions increased to $5.34 \times 10^{8}$ tons of China's industrial sectors during 2002-2010, though the carbon emissions reduced to $3.39 \times 10^{8}$ tons because of the carbon emission intensity effect; it is far less than the increase in carbon emissions caused by the effect of final demand; the value is $7.77 \times 10^{8}$ tons, and the effect of social technology has not contribute to the reduction of carbon emissions. When considering these three factors (CEE, TE and DE), the main factor leading to the increase of total carbon emissions in China's industrial sectors is the expanding final demand, which is related to the increasing population and gradually expanded consumption. Therefore, the reduction of carbon emissions in China's industrial sectors should be started from controlling the final demand 
TABLE 3: Structure decomposition analysis of the key sectors.

\begin{tabular}{|c|c|c|c|c|c|c|c|c|}
\hline \multirow{2}{*}{ Sectors } & \multicolumn{4}{|c|}{$2002-2007$} & \multicolumn{4}{|c|}{$2007-2010$} \\
\hline & $\triangle \mathrm{CEE}$ & $\Delta \mathrm{TE}$ & $\Delta \mathrm{DE}$ & $\Delta \mathrm{IC}$ & $\triangle \mathrm{CEE}$ & $\Delta \mathrm{TE}$ & $\Delta \mathrm{DE}$ & $\Delta \mathrm{IC}$ \\
\hline 16 & -226.36 & 114.8 & 792 & 680.44 & -238.64 & -45.55 & 801.57 & 517.39 \\
\hline 15 & -234.74 & 213.38 & 686.17 & 664.81 & -240.06 & 31.75 & 627.31 & 419.01 \\
\hline 17 & -169.93 & 147.92 & 674.47 & 652.46 & -206.71 & -31.31 & 679.19 & 441.18 \\
\hline 18 & -171.36 & 6.23 & 586.01 & 420.87 & -147.74 & -54.99 & 360.85 & 158.12 \\
\hline \multirow[t]{2}{*}{5} & -156.86 & 129.92 & 265.83 & 238.89 & -125.96 & 37.61 & 218.7 & 130.34 \\
\hline & $\triangle \mathrm{CEE}$ & $\Delta \mathrm{TE}$ & $\Delta \mathrm{DE}$ & $\Delta \mathrm{EC}$ & $\triangle \mathrm{CEE}$ & $\Delta \mathrm{TE}$ & $\Delta \mathrm{DE}$ & $\Delta \mathrm{EC}$ \\
\hline 16 & -9.3 & -0.93 & 111.15 & 100.93 & -55.85 & 26.8 & 119.99 & 90.94 \\
\hline 15 & -9.86 & 0.55 & 90.65 & 81.33 & -50.12 & 33.05 & 82.33 & 65.25 \\
\hline 17 & -6.53 & -0.38 & 83.05 & 76.14 & -40.58 & 23 & 84.15 & 66.58 \\
\hline 18 & -7.97 & -9.47 & 105.6 & 88.17 & -45.42 & 15.92 & 72.8 & 43.3 \\
\hline 5 & -29.09 & 14.79 & 131.52 & 117.22 & -62.13 & 26.62 & 109.48 & 73.96 \\
\hline
\end{tabular}

Note: unit is $10^{5}$ tons.

(such as recommending low carbon living). At the same time, technological innovations also should be strengthened; only in this way can we contribute to the reduction of total carbon emissions in China's industrial sectors.

Through splitting the study period into two time intervals, we can find that, in the first five years, the effect of carbon emission intensity has made the total carbon emissions of China's industrial sectors decreased $1.67 \times 10^{8}$ tons, while in the next three years, it has made the total carbon emissions of Chinese industrial sectors decreased $1.71 \times 10^{8}$ tons. It shows that the carbon emission intensity is gradually decreasing and promoting the reduction of carbon emissions. We also can know that the effect of social technology is gradually improved and conducive to the reduction of total carbon emissions in China's industrial sectors. While the contribution of the final demand to the carbon emissions is still increasing, we should pay more attention to controling it.

\section{Conclusions}

This paper has applied structural decomposition within an input-output subsystem model to show the reasons of the change of carbon emissions in China's industrial sectors between 2002 and 2010. The main conclusions are as follows. (1) Viewing from the three subsystem components (DLC, IC, and EC), we know that in the latest eight years the internal component of the industrial sectors is the main component leading to the increase of total carbon emissions in China; viewing from the department, we find that the department whose carbon emissions increased the most is the department whose direct and indirect carbon emissions increased the most, it is not only direct carbon emissions increased the most instead of direct carbon emissions increased the most. (2) When considering the following three factors: carbon intensity effect, social technological effect, and the effect of final demand, we find that the main reason leading to the increase of total carbon emissions is the expansion of final demand. (3) From the whole time (2002-2010) we know that the final demand effect contributed positively to carbon emission changes, with these effects being higher than the reduction caused by the carbon emission intensity effect, leading to an overall increase in carbon emissions. (4) From the analysis of the five key sectors we know that the social technology of industrial sectors is improving while the social technology of nonindustrial sectors is cutting down.

According to the results of this paper, in order to achieve our carbon reduction targets, on the one hand, we should focus on the five key sectors whose carbon emissions changed the most, controlling the exports of those products produced by these sectors strictly, encourage consumption of alternative products with low carbon emissions, and then achieve the purpose of reducing carbon emissions from the control of requirements. On the other hand, we should strengthen technological innovations. Material and spiritual rewards are given to the companies that achieved very good results on innovations, for example, reducing taxes on its products so they will have more funds for their technological innovations. We also can seek the support of advanced technology and capital from the developed countries to achieve the goal of emission reduction. Finally, we should pay attention to the control of the final demand of the products produced by the industrial sectors appropriately; we can also adjust the demand structure to reduce the carbon emissions or encourage people to use clean energy.

Our study has the following limitations. First, carbon emissions referred to in this paper only generated by energy consumption, failed to consider the production process which also generate carbon emissions. Second, our approach consists of a unique-region emission model; it cannot analyze the indirect emissions released in the supply chain outside the country. Thus, future work should pay special attention to the study of the carbon emissions by using a multiregional model which can consider the carbon emissions from import and export products, respectively, so we can understand the composition of carbon emissions in China's industrial sectors more clearly. In addition, carbon emissions from industrial sectors in China's different provinces should be studied, so we can develop appropriate low carbon policies and measures in accordance with the specific circumstances of different provinces. Finally, studies on other industries also should 
TABLE 4: The contribution of CEE, TE, and DE to the changes of total carbon emissions in China's industrial sectors.

\begin{tabular}{|c|c|c|c|c|c|c|c|}
\hline \multirow{2}{*}{ Sectors } & \multicolumn{2}{|c|}{$\triangle \mathrm{CEE}$} & \multicolumn{2}{|c|}{$\Delta \mathrm{TE}$} & \multicolumn{2}{|c|}{$\Delta \mathrm{DE}$} & \multirow{2}{*}{$\begin{array}{c}\text { Total } \\
2002-2010\end{array}$} \\
\hline & 2002-2007 & 2007-2010 & 2002-2007 & $2007-2010$ & 2002-2007 & 2007-2010 & \\
\hline 1 & -4.48 & 22.84 & 10.92 & -4.46 & -101.94 & -150.92 & -228.04 \\
\hline 2 & 151.08 & 27.47 & -116.48 & -57.3 & -305.87 & -94.22 & -395.31 \\
\hline 3 & 55.23 & 103.79 & -87.01 & -6.9 & -255.61 & -219.02 & -409.52 \\
\hline 4 & 2.27 & 3.73 & -1.82 & -2.25 & -18.17 & -9.89 & -26.14 \\
\hline 5 & -269.97 & -253.24 & 144.71 & 64.22 & 515.01 & 396.42 & 597.15 \\
\hline 6 & -113.65 & -121.38 & 83.76 & -15.01 & 362.91 & 53.29 & 249.93 \\
\hline 7 & -156.03 & -161.52 & 122.5 & 17.58 & 388.25 & 145.15 & 355.92 \\
\hline 8 & -42.83 & -45.32 & 31.08 & 23.74 & 169.7 & 29.97 & 166.35 \\
\hline 9 & -33.09 & -27.75 & 28.49 & 5.93 & 39.59 & 11.48 & 24.64 \\
\hline 10 & 24.51 & 11.79 & -7.49 & 2.64 & -91.66 & -43.09 & -103.29 \\
\hline 11 & -21.1 & -14.37 & 12.71 & 0.29 & -24.63 & 30.84 & -16.27 \\
\hline 12 & -52.26 & -27.54 & 18.66 & 7.63 & 42.04 & -26.19 & -37.67 \\
\hline 13 & 28.29 & 38.29 & -17.53 & 4.51 & 77.75 & -270.61 & -139.3 \\
\hline 14 & -85.85 & -62.02 & 36.35 & 9.14 & 323.04 & -66.54 & 154.13 \\
\hline 15 & -267.66 & -325.21 & 213.93 & 64.8 & 854.45 & 767.95 & 1308.26 \\
\hline 16 & -288.11 & -309.39 & 113.88 & -18.74 & 989.85 & 984.39 & 1471.88 \\
\hline 17 & -191.56 & -256.64 & 147.54 & -8.31 & 797.15 & 794.45 & 1282.64 \\
\hline 18 & -191.9 & -198.79 & -3.24 & -39.08 & 727.73 & 456.35 & 751.08 \\
\hline 19 & -10.87 & -6.66 & 6.3 & -3.41 & 25.95 & -9.63 & 1.68 \\
\hline 20 & -109.56 & -68.22 & 53.13 & 54.17 & 226.84 & 129.66 & 286.02 \\
\hline 21 & 2.62 & 2.68 & -6.62 & 2.27 & -6.62 & -14.06 & -19.72 \\
\hline 22 & -70.12 & -19.94 & 55.67 & 5.36 & 0.89 & -0.75 & -28.88 \\
\hline 23 & -20.68 & -18.03 & 2.84 & -1.55 & 19.14 & 48.68 & 30.4 \\
\hline 24 & -6.15 & -9.26 & 2.55 & 2.2 & 17.96 & 52.2 & 59.52 \\
\hline Total & -1671.87 & -1714.69 & 844.83 & 107.48 & 4773.78 & 2995.92 & 5335.45 \\
\hline
\end{tabular}

Note: unit is $10^{5}$ tons.

be conducted to illustrate the characteristics of main contributors to carbon emissions. At the same time, we should do more researches on the development and evaluation of low carbon policies. Because most of the current studies are just staying in the phase of phenomenon analysis, they lack specific policy implementation and evaluation system.

\section{Conflict of Interests}

The authors declare that there is no conflict of interests regarding the publication of this paper.

\section{Acknowledgments}

This paper is financially supported by the National Natural Science Foundation of China (71103077), Science Foundation of Ministry of Education of China (10YJC630377), and China Postdoctoral Science Foundation (2012M512015).

\section{References}

[1] S. Liang and T. Zhang, "What is driving $\mathrm{CO}_{2}$ emissions in a typical manufacturing center of South China? The case of Jiangsu Province," Energy Policy, vol. 39, no. 11, pp. 7078-7083, 2011.
[2] S. Y. Chen, "Green industrial revolution in China: a perspective from the change of environmental total factor productivity," Economic Research, vol. 45, no. 11, pp. 21-34, 2010.

[3] J. W. Wen, China Energy Statistic Year Book 2012, China Statistics Press, 2012.

[4] S. G. Ren, H. Y. Yin, and X. H. Chen, "Using LMDI to analyze the decoupling of carbon dioxide emissions by China's manufacturing industry," Environmental Development, vol. 9, pp. 61-75, 2014.

[5] B. Lin and M. Moubarak, "Decomposition analysis: change of carbon dioxide emissions in the Chinese textile industry," Renewable and Sustainable Energy Reviews, vol. 26, pp. 389-396, 2013.

[6] M. Zhao, L. Tan, W. Zhang, M. Ji, Y. Liu, and L. Yu, "Decomposing the influencing factors of industrial carbon emissions in Shanghai using the LMDI method," Energy, vol. 35, no. 6, pp. 2505-2510, 2010.

[7] C. Shao, Y. Guan, Z. Wan, C. Guo, C. Chu, and M. Ju, "Performance and decomposition analyses of carbon emissions from industrial energy consumption in Tianjin, China," Journal of Cleaner Production, vol. 64, pp. 590-601, 2014.

[8] C. Sheinbaum-Pardo, S. Mora-Pérez, and G. Robles-Morales, "Decomposition of energy consumption and $\mathrm{CO}_{2}$ emissions in Mexican manufacturing industries: trends between 1990 and 2008," Energy for Sustainable Development, vol. 16, no. 1, pp. 5767, 2012. 
[9] E. Akbostanci, G. I. Tunç, and S. Türüt-Aşik, "CO 2 emissions of Turkish manufacturing industry: a decomposition analysis," Applied Energy, vol. 88, no. 6, pp. 2273-2278, 2011.

[10] G. P. Hammond and J. B. Norman, "Decomposition analysis of energy-related carbon emissions from UK manufacturing," Energy, vol. 41, no. 1, pp. 220-227, 2012.

[11] A. Priambodo and S. Kumar, "Energy use and carbon dioxide emission of Indonesian small and medium scale industries," Energy Conversion and Management, vol. 42, no. 11, pp. 13351348, 2001.

[12] Y. H. Huang and J. H. Wu, "Analyzing the driving forces behind $\mathrm{CO}_{2}$ emissions and reduction strategies for energy-intensive sectors in Taiwan: 1996-2006," Energy, vol. 57, pp. 402-411, 2013.

[13] D. González and M. Martínez, "Decomposition analysis of $\mathrm{CO}_{2}$ emissions in the Mexican industrial sector," Energy for Sustainable Development, vol. 16, no. 2, pp. 204-215, 2012.

[14] J. Caiman and p. Brian, "Combining physical and economic output data to analyze energy and $\mathrm{CO}_{2}$ emissions trends in industry," Energy Policy, vol. 49, pp. 422-429, 2012.

[15] P. Yuan and S. Cheng, "Determinants of Carbon Emissions Growth in China: A structural decomposition analysis," Energy Procedia, vol. 5, pp. 169-175, 2011.

[16] X. Zhao, N. Li, and C. Ma, "Residential energy consumption in urban China: a decomposition analysis," Energy Policy, vol. 41, pp. 644-653, 2012.

[17] X. Tian, M. Chang, H. Tanikawa, F. Shi, and H. Imura, "Structural decomposition analysis of the carbonization process in Beijing: a regional explanation of rapid increasing carbon dioxide emission in China," Energy Policy, vol. 53, pp. 279-286, 2013.

[18] D. Guan, K. Hubacek, C. L. Weber, G. P. Peters, and D. M. Reiner, "The drivers of Chinese $\mathrm{CO}_{2}$ emissions from 1980 to 2030," Global Environmental Change, vol. 18, no. 4, pp. 626-634, 2008.

[19] J. Brizga, K. Feng, and K. Hubacek, "Drivers of greenhouse gas emissions in the Baltic States: a structural decomposition analysis," Ecological Economics, vol. 98, pp. 22-28, 2014.

[20] M. Cellura, S. Longo, and M. Mistretta, "Application of the structural decomposition analysis to assess the indirect energy consumption and air emission changes related to Italian households consumption," Renewable and Sustainable Energy Reviews, vol. 16, no. 2, pp. 1135-1145, 2012.

[21] R. Wood, "Structural decomposition analysis of Australia's greenhouse gas emissions," Energy Policy, vol. 37, no. 11, pp. 4943-4948, 2009.

[22] V. Alcántara and E. Padilla, "Input-output subsystems and pollution: an application to the service sector and $\mathrm{CO}_{2}$ emissions in Spain," Ecological Economics, vol. 68, no. 3, pp. 905-914, 2009.

[23] M. A. Cardenete and P. Fuentes, "Energy consumption and $\mathrm{CO}_{2}$ emissions in the Spanish economy," in Air Pollution: Measurements and Control Policies, M. Llop, Ed., Bentham EBooks, 2011.

[24] I. Butnar and M. Liop, "Structural decomposition analysis and input-output subsystems: changes in $\mathrm{CO}_{2}$ emissions of Spanish service sectors (2000-2005)," Ecological Economics, vol. 70, no. 11, pp. 2012-2019, 2011.

[25] X. K. Chen and C. H. Yang, Input-Output Technology, Science Press of China, 2011.

[26] National Bureau of Statistics of the People's Republic of China, http://www.stats.gov.cn/.

[27] Q. Liu and Z. Peng, China 1992-2005 Comparable Price InputOutput Series Tables and Analysis, China Statistics Press, 2010. 


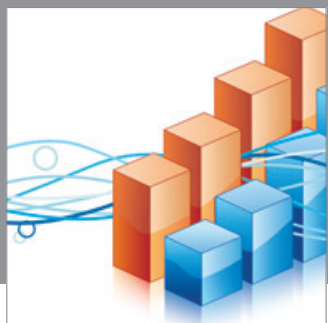

Advances in

Operations Research

mansans

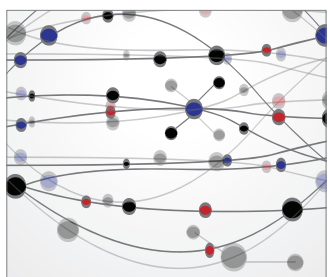

The Scientific World Journal
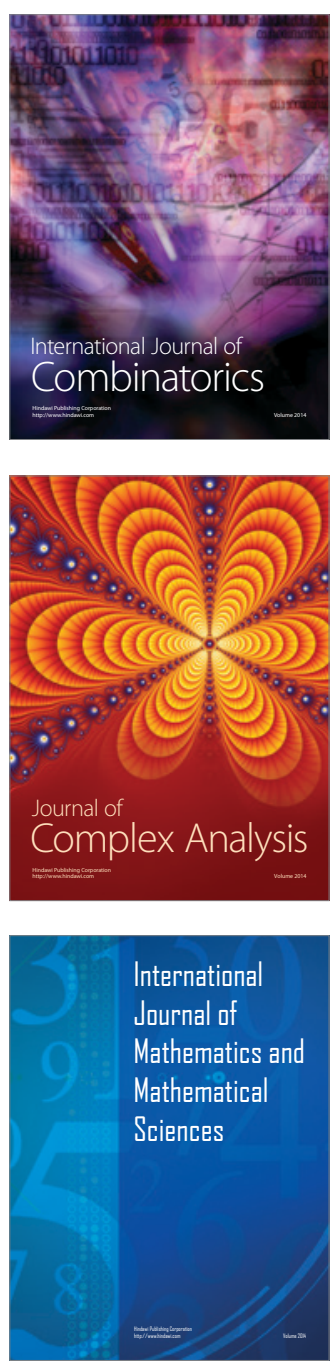
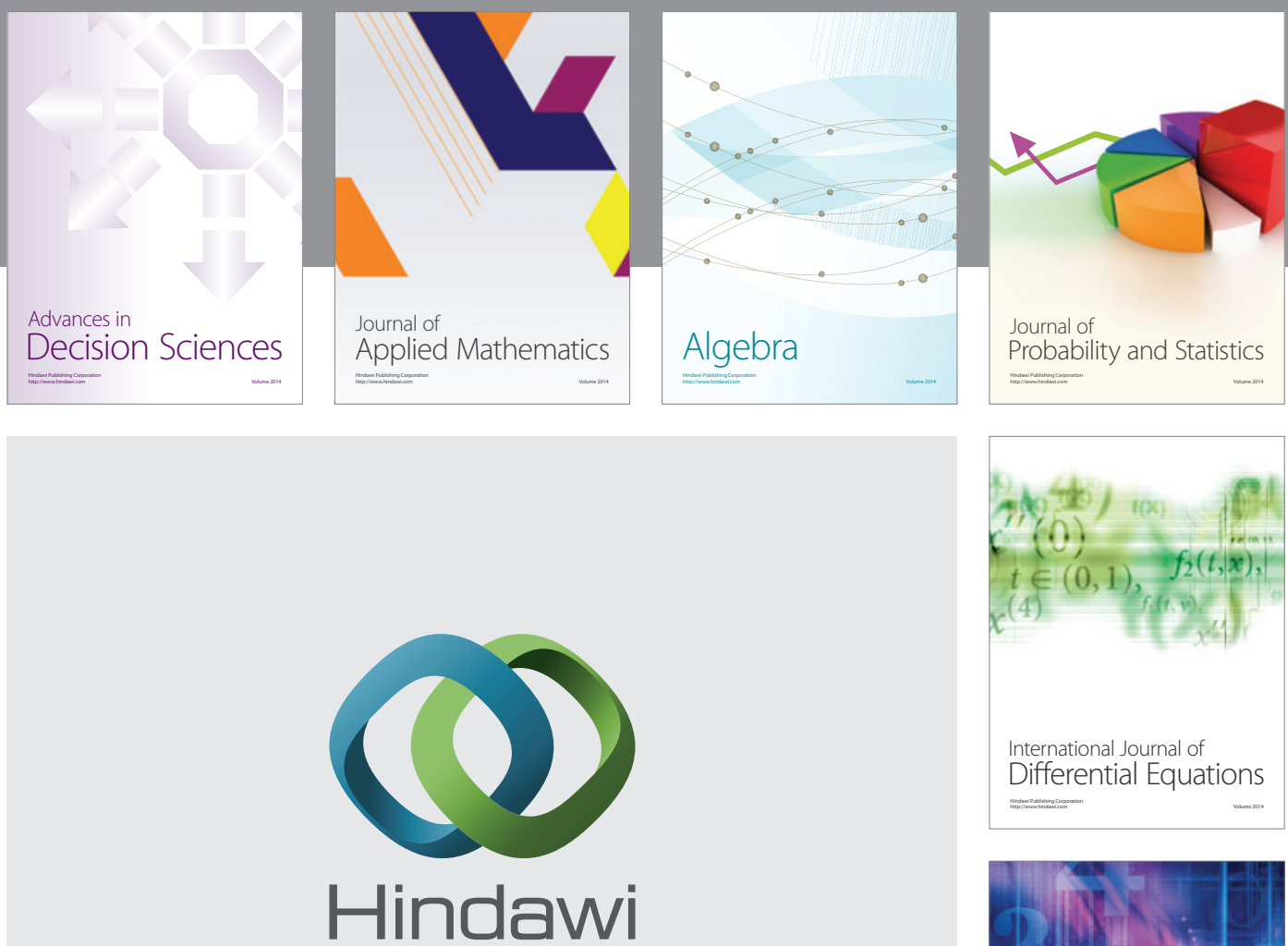

Submit your manuscripts at http://www.hindawi.com
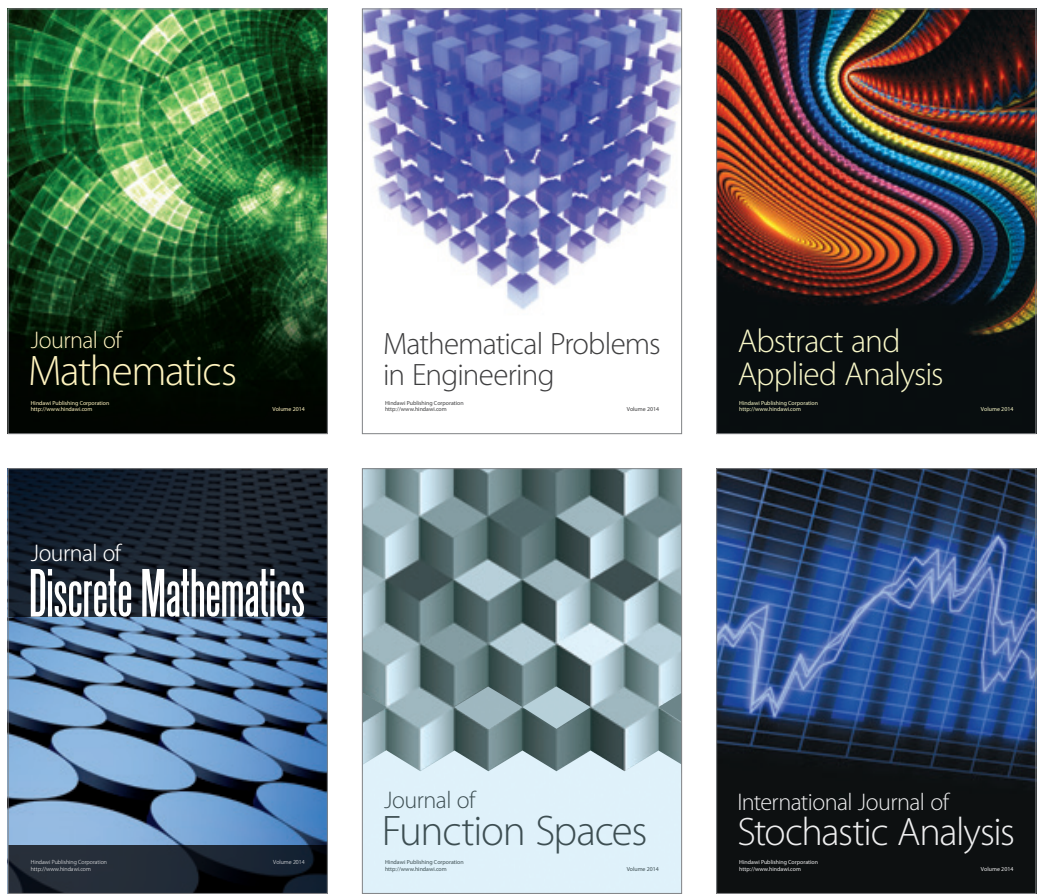

Journal of

Function Spaces

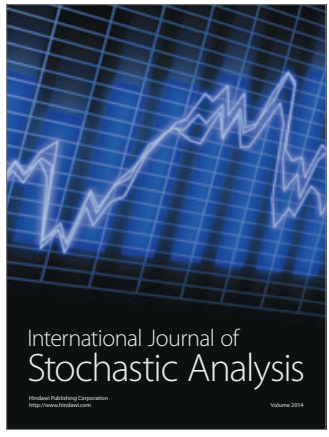

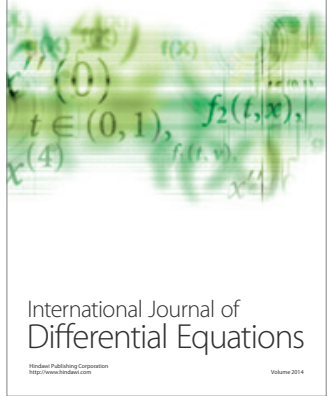
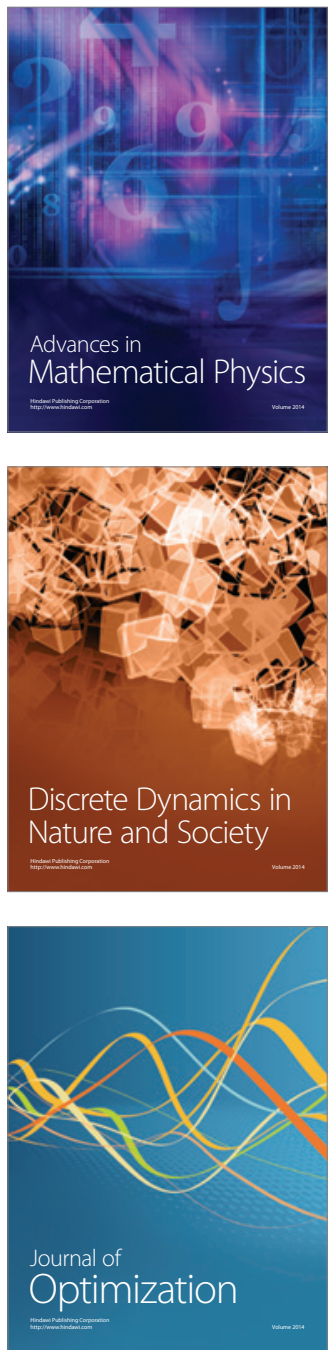